\title{
Retention of high tactile acuity throughout the life span in blindness
}

\author{
Gordon E. Legge, Cindee Madison, Brenna N. Vaughn, \\ Allen M.Y. Cheong, And Joseph C. Miller \\ University of Minnesota, Minneapolis, Minnesota
}

\begin{abstract}
Previous studies of tactile acuity on the fingertip, using passive touch, have demonstrated an age-related decline in spatial resolution for both sighted and blind subjects. We have reexamined this age dependence with two newly designed tactile-acuity charts that require active exploration of the test symbols. One chart used dot patterns similar to braille, and the other used embossed Landolt rings. Groups of blind braille readers and sighted subjects ranging from 12 to 85 years old were tested in two experiments. We replicated previous findings for sighted subjects by showing an age-related decrease in tactile acuity by nearly $1 \%$ per year. Surprisingly, the blind subjects retained high acuity into old age, showing no age-related decline. For the blind subjects, tactile acuity did not correlate with braille reading speed, the amount of daily reading, or the age at which braille was learned. We conclude that when measured with active touch, blind subjects retain high tactile acuity into old age, unlike their aging sighted peers. We propose that blind people's use of active touch in daily activities, not specifically braille reading, results in preservation of tactile acuity across the life span.
\end{abstract}

Blind people rely more heavily on nonvisual sensory information than sighted people do. Until recently, it was widely believed that auditory and tactile detection and simple discrimination thresholds are similar in both blind and sighted subjects (see Hollins, 1989, for a review).

Several recent studies using modern psychophysical methods have shown that tactile spatial resolution is better in blind subjects than in age-matched sighted subjects (Goldreich \& Kanics, 2003, 2006; Stevens, Foulke, \& Patterson, 1996; Van Boven, Hamilton, Kauffman, Keenan, \& Pascual-Leone, 2000). Grant, Thiagarajah, and Sathian (2000), however, did not find a blind-sighted difference.

The ability to measure small group differences in tactile spatial thresholds has benefited from the realization that the traditional two-point threshold method is confounded by nonspatial intensity and other cues (Craig \& Johnson, 2000). Preferred methods for measuring spatial resolution on the skin include gap detection (Stevens \& Choo, 1996) and grating-orientation threshold discrimination (Johnson \& Phillips, 1981). In gap detection, an edge that either is solid or contains a gap is pressed against the skin. Gap width is varied in order to find a threshold size. Grating-orientation thresholds are measured with tactile gratings consisting of alternating grooves and ridges that produce a periodic pattern. The gratings are pressed against the skin in one of two orthogonal orientations, and the groove and ridge width is varied in order to find the threshold for orientation discrimination. These methods assess the capacity of the skin to detect the presence and orientation of small spatial intervals. The resulting thresholds are consistent with the receptor density of the slowly adapting type I (SAI) mechanoreceptors on the fingertip that are thought to be responsible for spatial acuity on the skin (Johnson \& Hsiao, 1992).

As summarized in Table 1, recent measurements of spatial thresholds on the fingertip range from about 1.2 to $1.7 \mathrm{~mm}$ for young, normally sighted subjects. The thresholds for blind subjects are roughly $0.2 \mathrm{~mm}$ lower, ranging from about 1.0 to $1.5 \mathrm{~mm}$, representing about $15 \%$ better tactile acuity. Undoubtedly, some of the numerical differences across studies in Table 1 are due to methodological differences. These differences also indicate the need for caution in interpreting the relationship between tactile acuity and braille reading discussed below.

Braille is the most successful code for reading by touch. Braille is not a language (like English or Spanish) but a code for representing the written form of a language with tactile symbols. Braille characters consist of combinations of six dots, placed in a matrix of two columns and three rows, termed a braille cell (Figure 1). The 64 possible arrangements of dots in the braille cell (including the blank cell) represent the 64 characters of the braille code. Twenty-six of these characters represent the 26 letters of the English alphabet.

Identification of braille characters relies on the reader's ability to discern the number and spatial arrangement of dots in the braille cell. As illustrated in Figure 1, the critical features of the cell (the dots) are located in a matrix with a center-to-center spacing of $2.28 \mathrm{~mm}$ between near-

G. E. Legge, legge@umn.edu 
Table 1

Summary of Tactile-Acuity Thresholds (in Millimeters) on the Fingertip, From Recent Studies

\begin{tabular}{|c|c|c|c|c|}
\hline \multirow[b]{2}{*}{ Study } & \multirow[b]{2}{*}{ Threshold Method } & \multirow[b]{2}{*}{ Subject Group } & \multicolumn{2}{|c|}{ Threshold } \\
\hline & & & $M$ & $S E$ \\
\hline Dinse et al. (2006) & $\begin{array}{l}\text { Discrimination of } \\
1 \text { or } 2 \text { points }\end{array}$ & $\begin{array}{l}\text { Younger sighted } \\
\text { Older sighted }\end{array}$ & $\begin{array}{l}1.58 \\
3.40\end{array}$ & $\begin{array}{l}0.02 \\
0.09\end{array}$ \\
\hline Goldreich \& Kanics (2003)a & $\begin{array}{l}\text { Grating orientation } \\
\text { threshold }\end{array}$ & $\begin{array}{l}\text { Younger sighted } \\
\text { Older sighted } \\
\text { Younger blind } \\
\text { Older blind }\end{array}$ & $\begin{array}{l}1.65 \\
2.62 \\
1.49 \\
2.01\end{array}$ & \\
\hline $\begin{array}{l}\text { Grant, Thiagaraja, \& Sathian } \\
\text { (2000, Experiment 3) }\end{array}$ & $\begin{array}{l}\text { Grating orientation } \\
\text { threshold }\end{array}$ & $\begin{array}{l}\text { Sighted } \\
\text { Blind }\end{array}$ & $\begin{array}{l}1.35 \\
1.28\end{array}$ & $\begin{array}{l}0.13 \\
0.11\end{array}$ \\
\hline $\begin{array}{l}\text { Ragert, Schmidt, Altenmüller, } \\
\text { \& Dinse (2004) }\end{array}$ & $\begin{array}{l}\text { Discrimination of } \\
1 \text { or } 2 \text { points }\end{array}$ & $\begin{array}{l}\text { Younger sighted pianists } \\
\text { Younger sighted nonmusicians }\end{array}$ & $\begin{array}{l}1.11 \\
1.61\end{array}$ & $\begin{array}{l}0.12 \\
0.04\end{array}$ \\
\hline $\begin{array}{l}\text { Stevens, Foulke, \& Patterson } \\
\quad(1996, \text { Experiment 2) }\end{array}$ & $\begin{array}{l}\text { Gap detection } \\
\text { threshold }\end{array}$ & $\begin{array}{l}\text { Younger sighted } \\
\text { Older sighted } \\
\text { Younger blind } \\
\text { Older blind }\end{array}$ & $\begin{array}{l}1.59 \\
2.81 \\
1.18 \\
2.48\end{array}$ & \\
\hline $\begin{array}{l}\text { Van Boven, Hamilton, Kauffman, } \\
\text { Keenan, \& Pascual-Leone (2000) }\end{array}$ & $\begin{array}{l}\text { Grating orientation } \\
\text { threshold }\end{array}$ & $\begin{array}{l}\text { Blind } \\
\text { Sighted }\end{array}$ & $\begin{array}{l}1.04 \\
1.46\end{array}$ & $\begin{array}{l}0.05 \\
0.12\end{array}$ \\
\hline Vega-Bermudez \& Johnson (2004) & $\begin{array}{l}\text { Grating orientation } \\
\text { threshold }\end{array}$ & $\begin{array}{l}\text { Younger sighted } \\
\text { Older sighted }\end{array}$ & $\begin{array}{l}1.21 \\
1.97\end{array}$ & $\begin{array}{l}0.08 \\
0.12\end{array}$ \\
\hline
\end{tabular}

avalues for Goldreich and Kanics (2003) were derived from regression lines for threshold versus age for blind and sighted groups, with "younger" values being the thresholds at 25 years of age and "older" values being the thresholds at 75 years of age. The individual data (thresholds for 50-g contact force) were provided by Daniel Goldreich (personal communication, December 13, 2007). bStandard errors $(S E)$ were not available for these thresholds.

est neighbors. It is reasonable to expect that a prerequisite for fluent reading would be tactile acuity adequate for resolving spatial details on this scale. The estimates of spatial tactile acuity in younger sighted and blind subjects (Table 1) are roughly half the center-to-center dot spacing of $2.28 \mathrm{~mm}$ within the braille cell, representing a tolerance of a factor of only two for identifying braille symbols. It

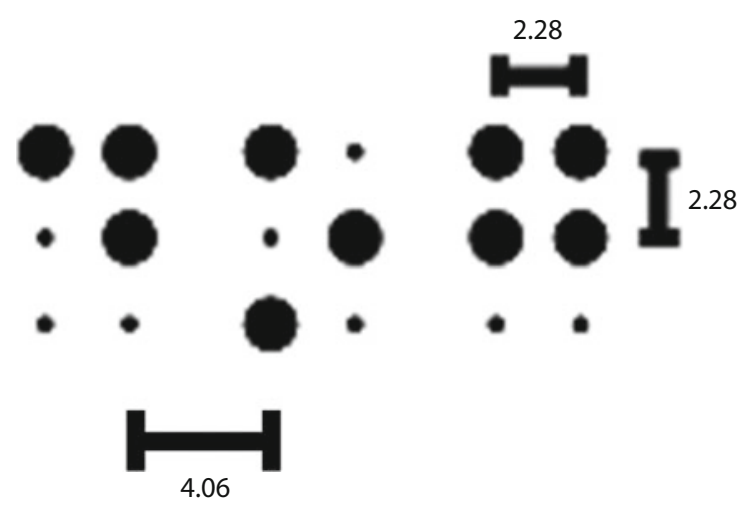

Figure 1. Three adjacent braille cells are shown, illustrating the standard dimensions of the braille cell and the rendering of the three-letter word "dog." There are six possible dot positions in each braille cell; the larger black circles represent the dots in the character, and the smaller black circles represent the unused dot positions. For instance, the braille character consisting of the top four dots of the right-hand cell represents the letter "g." According to Nolan and Kederis (1969), individual dots have a base diameter of $1.5 \mathrm{~mm}$ and a height above the surface of the page of $0.43 \mathrm{~mm}$. Horizontally or vertically adjacent dots within a cell have a center-to-center separation of $2.28 \mathrm{~mm}$. is evident that recognition of characters in braille reading operates close to the tactile acuity limit.

The constraints imposed by tactile acuity may be more severe for older braille readers because of the known agerelated decline in tactile acuity (Table 1). Stevens et al. (1996) reported that both blind and sighted subjects display an age-related decline in tactile acuity for gap detection. This decline occurs at different rates all over the body, with acuity on the fingertip decreasing at a rate of about $1 \%$ per year (Stevens, 1992; Stevens \& Choo, 1996; Stevens et al., 1996). An increase of $1 \%$ per year in the threshold spatial interval for tactile resolution would result in an $80 \%$ increase in tactile thresholds from 20 to 80 years of age. Stevens et al. (1996, Experiment 2) reported an increase in mean tactile threshold from $1.18 \mathrm{~mm}$ for their younger blind group to $2.48 \mathrm{~mm}$ for their older blind group. Goldreich and Kanics (2003), using grating-orientation discrimination, also observed a decline in tactile acuity between 25 years and 75 years, from 1.65 to $2.62 \mathrm{~mm}$ for their sighted subjects and from 1.49 to $2.01 \mathrm{~mm}$ for their blind subjects. In another study, Goldreich and Kanics (2006) found a similar agerelated pattern, using a tactile grating-detection method.

The above review reveals a problem in our understanding of the relationship between braille reading and tactile acuity. It is evident that braille characters are only slightly above the acuity limit for younger blind readers and close to or beyond the acuity limit for older braille readers. If this is the case, braille reading should become progressively more difficult in old age, and many older blind individuals should lose the sensory capacity to read braille. It is notoriously difficult for late-blinded individuals to learn braille in old age, and we are unaware of evidence that people who learn braille early in life and who retain good skin health become unable to read braille in old age. ${ }^{1}$ Stevens et al. 
(1996) considered this issue in their study of aging effects on tactile acuity in sighted and blind subjects. The correlations among braille reading speed, age, and tactile acuity among their blind subjects were surprisingly weak or absent, depending on the conditions. Stevens et al. (1996) were puzzled by the lack of a more robust relationship between age and braille reading performance and recommended the development of a tactile-acuity chart, similar to the Snellen letter chart for visual acuity, for assessing the adequacy of spatial resolution for braille reading.

In two experiments, we measured tactile acuity for blind and sighted subjects on two newly designed tactile-acuity charts. One of the charts used braille-like symbols comprising dot patterns. Using this chart, we found the previously observed decline in tactile acuity with age among sighted subjects. Surprisingly, the results revealed retention of high tactile acuity in old age among braille readers. To determine whether this unexpected result was specific to the highly familiar and linguistically laden attributes of the braille test symbols, we designed a second chart composed of symbols (Landolt rings) likely to be less familiar and less linguistically salient to braille readers. Once again, the results revealed retention of high tactile acuity in old age among the braille readers. Our surprising results conflict with the observed age-related decline in tactile acuity among blind subjects (Goldreich \& Kanics, 2003, 2006; Stevens et al., 1996), but may help to explain why many blind people continue to read braille successfully into old age.

\section{EXPERIMENT 1 \\ Tactile Acuity As a Function of Age, Using the Dot Chart}

We investigated the relationship between tactile acuity and age in blind braille readers and sighted subjects, using a newly designed chart composed of symbols similar to characters used in braille reading.

\section{Method}

Subjects. Subject characteristics are summarized in Table 2 .

Forty-nine blind braille readers (age range, 18-74 years) and 83 sighted non-braille readers (age range, $12-82$ years) participated in the study. All subjects reported having normal, healthy hands. ${ }^{2}$ Of the 49 braille readers, 13 had some level of light perception, 33 had no residual vision, and 3 had low vision sufficient to read highly magnified print. ${ }^{3}$ All subjects gave informed consent, and the study protocol was approved by the University of Minnesota's Institutional Review Board.

The subjects were allowed to choose their preferred hand for testing. Sighted subjects chose their dominant hand. Blind subjects chose their preferred hand for braille reading, which was not always the dominant hand (according to other tests).

The blind subjects completed a questionnaire concerning the age of vision impairment onset, the age at which braille instruction began, and the amount of daily braille reading. The blind subjects were also given a test of braille reading speed, using the MNREAD test, as part of a parallel study of reading speed (Legge, Madison, \& Mansfield, 1999). All but 7 blind subjects had learned braille before 15 years of age; the average age of first exposure was 9.5 ( $S D=8.8$ years). The average braille reading speed was 114 words/ $\min ($ range $=14-228)$

Stimuli. The dot charts were made on a carbon/plastic sheet. Two versions of the chart, with different random sequences of test symbols, were constructed (Figure 2A). The test symbols were four three-dot patterns that corresponded to four braille letters $(j, h, d$, $f$ ), matched for legibility (Nolan \& Kederis, 1969). Each of the four characters uses three of the top four dots in the braille cell and differs only in the spatial location of the missing fourth dot.

Each chart had nine lines of eight characters: Dot separations decreased by $0.1 \log$ unit $(26 \%)$ per line. The dot spacing on the sixth line, labeled 0 (Figure 2A), corresponded to that of standard braille characters (i.e., center-to-center spacing between nearest neighbor dots of $2.28 \mathrm{~mm}$ ). Logarithmic spacing with a step size of $0.1 \mathrm{log}$ unit follows the common design principle for modern logMAR letteracuity charts (see Ferris, Kassoff, Bresnick, \& Bailey, 1982). Labeling standard braille as the reference line at $0 \log$ units is analogous to the common practice of labeling the line with Snellen 20/20 letters (subtending $5^{\prime}$ of arc) as the $0 \log$ unit line on visual letter-acuity charts.

Dot amplitude and shape remained constant on all lines of the chart. A consequence of retaining invariant dot size was that lines with dot spacing less than $-0.3 \log$ unit (with center-to-center dot separation of $1.14 \mathrm{~mm}$ ) had overlapping dots, which compromised character shape. As a result, the last line on the chart was at $-0.3 \log$ unit.

Tests were scored on a logarithmic scale, following standard methods for scoring visual acuity on a letter-by-letter basis (Ferris et al., 1982). Each line was worth $0.1 \mathrm{log}$ unit, and each symbol measured $1 / 8$ of one line $(0.0125 \log$ unit). Beginning with a starting score of -0.3 representing perfect performance on all lines of the chart, 0.0125 was added for each missed or inaccurately recognized symbol $[$ score $=-0.3+($ number of errors $\times 0.0125)]$. For example, a

Table 2

Characteristics of the Subjects in Experiment 1

\begin{tabular}{|c|c|c|c|c|c|c|c|c|c|c|c|c|c|c|c|c|}
\hline \multirow[b]{4}{*}{ Subjects } & \multicolumn{10}{|c|}{ Demographic } & \multicolumn{6}{|c|}{ Median Tactile Acuity } \\
\hline & \multirow{2}{*}{\multicolumn{3}{|c|}{ Age (Years) }} & \multirow{2}{*}{\multicolumn{2}{|c|}{ Gender }} & \multirow{2}{*}{\multicolumn{2}{|c|}{ Hand Used }} & \multicolumn{3}{|c|}{ Vision Status } & \multicolumn{2}{|c|}{ All } & \multicolumn{2}{|c|}{ Females } & \multicolumn{2}{|c|}{ Males } \\
\hline & & & & & & & & \multirow{2}{*}{$\begin{array}{l}\text { None/Light } \\
\text { Perception }\end{array}$} & \multirow[b]{2}{*}{ Low } & \multirow[b]{2}{*}{ Normal } & \multirow{2}{*}{$\begin{array}{c}\text { Log } \\
\text { Units }\end{array}$} & \multirow[b]{2}{*}{ IQR } & \multirow{2}{*}{$\begin{array}{l}\text { Log } \\
\text { Units }\end{array}$} & \multirow[b]{2}{*}{ IQR } & \multirow{2}{*}{$\begin{array}{l}\text { Log } \\
\text { Units }\end{array}$} & \multirow[b]{2}{*}{ IQR } \\
\hline & $M$ & $S D$ & Range & Female & Male & Right & Left & & & & & & & & & \\
\hline \multicolumn{17}{|c|}{ Index Finger } \\
\hline $\begin{array}{l}\text { Blind } \\
\qquad(n=49)\end{array}$ & 44.3 & 15.2 & $18-74$ & 10 & 39 & 26 & 23 & 46 & 3 & 0 & -0.275 & 0.025 & -0.264 & 0.053 & -0.275 & 0.025 \\
\hline $\begin{array}{l}\text { Sighted } \\
\qquad(n=83)\end{array}$ & 40.1 & 21.2 & $12-82$ & 47 & 36 & 74 & 9 & 0 & 0 & 83 & -0.150 & 0.126 & -0.150 & 0.125 & -.0144 & 0.141 \\
\hline \multicolumn{17}{|c|}{ Ring Finger } \\
\hline $\begin{array}{l}\text { Blind } \\
\quad(n=21)\end{array}$ & 46.4 & 15.9 & $23-71$ & 5 & 16 & 11 & 10 & 20 & 1 & 0 & -0.238 & 0.071 & -0.150 & 0.131 & -0.250 & 0.067 \\
\hline $\begin{array}{l}\text { Sighted } \\
\qquad(n=23)\end{array}$ & 38.4 & 16.7 & $12-70$ & 14 & 9 & 20 & 3 & 0 & 0 & 23 & -0.125 & 0.188 & -0.163 & .0172 & -0.068 & 0.250 \\
\hline
\end{tabular}

Note-IQR, interquartile range. 
A
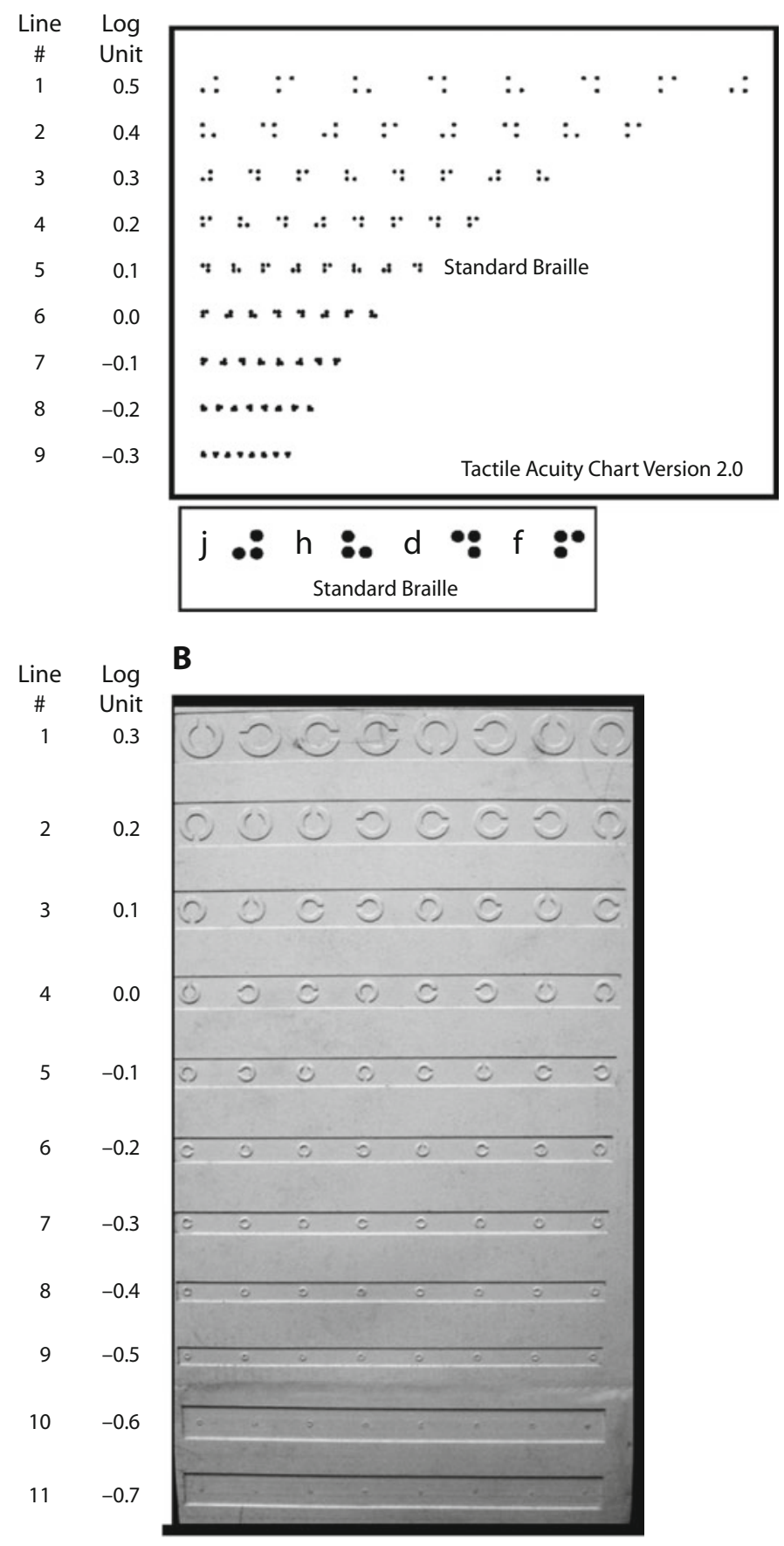

Figure 2. Illustration of the dot chart (top) used in both experiments, and the ring chart (bottom) used in Experiment 2. Both charts are composed of four symbols arranged in rows of decreasing size in 0.1 log-unit steps $(26 \%$ change in size). Line 6 of the dot chart is used as a reference ( 0 log units) and has symbols from the standard braille alphabet $(j, h, d, f)$ as shown beneath the chart. On this line, the center-to-center dot spacing is $2.28 \mathrm{~mm}$. Line 4 on the ring chart is the reference line $(0 \log$ units) and has rings with gaps of $2.4 \mathrm{~mm}$, nearly matched to the dot spacing on the reference line of the dot chart. See the text for other details of chart design. 
subject who missed all eight symbols on the $-0.3 \log$ unit line, but recognized all other symbols correctly, would have an acuity score of $-0.3+(8 \times 0.0125)=-0.2 \log$ unit.

Procedure. The chart was placed flat on the table in front of the subject. The subject reached beneath an occluding black felt cloth that was supported by a frame, which blocked the view of the hands and chart for the sighted subjects.

Blind subjects read through the test lines and reported aloud the corresponding braille letters $(j, h, d, f)$. Sighted subjects were given the option of reporting the location of the missing dot (e.g., "lower left," corresponding to the braille symbol $d$ ) or using a legend depicting the dot patterns with the corresponding braille letter to match their tactile input. The test was not timed, and accuracy was stressed over speed.

Following testing on the index finger, some of the subjects (21 blind, 23 sighted) were then tested on their ring finger (the finger next to the little finger) on the same hand. Subjects were urged to use only the ring finger and were closely monitored by the experimenter.

For both the blind and sighted groups, tactile acuities measured in the index and ring finger data sets were resampled 1,000 times with replacement, using a bootstrap method developed by Efron and Tibshirani (1993). Tactile acuities measured in the index and ring fingers were resampled 1,000 times. Each resampled data set was then analyzed with jackknife resampling techniques in MATLAB 7 (with the Statistics Toolbox) to estimate the regression statistics and correct for any bias. Each resampling produced a regression line for tactile acuity versus age, and the cluster of regression lines for a group and finger used provided a measure of variability. Confidence intervals $(95 \%)$ were calculated and are displayed in Figure 3, showing the dispersion of the resampled regression lines.

\section{Results}

Figure 3A shows tactile acuities for 49 blind subjects and 83 sighted subjects, as a function of age, measured with the dot chart. Best fitting regression lines are shown for the two groups: dark for blind, dashed for sighted. The gray bands show $95 \%$ confidence intervals: dark gray for blind, light gray for sighted. The left vertical scale represents the centerto-center spacing between nearest dots on a log scale, with the spacing for the standard braille cell $(2.28 \mathrm{~mm})$ assigned the value $0 \log$ unit. On this scale, larger values represent larger gap size (i.e., poorer acuity). Values larger than 0 represent symbols at the acuity limit that are larger than standard braille characters. The right vertical scale shows corresponding dot spacing in millimeters.

The rising regression line for the sighted subjects represents a progressive decrease in tactile acuity (increase in dot spacing at the acuity limit) with age. The slope is $0.0037 \log$ unit per year (linear regression model, $p<$ .001 ). This slope is equivalent to a change of $0.86 \%$ per year, close to the approximate value of $1 \%$ decline per year in tactile acuity on the fingertip, observed by Stevens and Patterson (1995). For sighted subjects, the change from a tactile acuity of $-0.20 \log$ unit at 20 years of age to +0.03 $\log$ unit at 80 years of age corresponds to an increase in the threshold dot spacing from $1.44 \mathrm{~mm}$ to $2.44 \mathrm{~mm}$.

We found it surprising that the braille readers exhibited no decrease in acuity with age (linear regression model, $p=.77)$. The mean acuity across all 49 subjects was $-0.27 \log$ unit, corresponding to a threshold dot spacing of $1.22 \mathrm{~mm}$. The tactile acuities of the braille reading group were better than those of the sighted group at all ages. At age 20, the difference was $0.08 \log$ unit, which corresponds to about a $20 \%$ difference in dot spacing, and at age 80 , the difference was $0.30 \log$ unit, corresponding to a $100 \%$ difference in dot spacing. The separation between the data for the sighted and the blind subjects is clear: The $95 \%$ confidence limits on the regression lines do not overlap above 20 years of age.

The narrow confidence limits on the data for the blind subjects may reveal a floor effect that is due to the design of the chart. As described in the Method section, we could not include lines smaller than $-0.3 \log$ unit without overlap of the dots, which would destroy the character shape. Seven of the blind subjects were correct on all eight characters on the $-0.3 \log$ unit line. Across all 49 blind subjects, performance on the -0.3 line was $75.3 \%$ correct, compared with a chance accuracy of $25 \%$ correct. We will return to the impact of this floor effect in the Discussion of Experiment 1 below.

For the blind subjects, the hand used, the age at which braille was learned, years of braille reading, years of blindness, braille reading speed, status of residual vision, gender, and hours of reading per week were not significant in predicting tactile acuity $(p>.06)$. For the sighted subjects, gender did not correlate with acuity $(p=.70)$. Age was the major predictor for acuity $\left(r_{\mathrm{s}}=.62, p<.001\right)$. Figure $3 \mathrm{~B}$ shows tactile acuities of the ipsilateral ring finger, which is generally not used in braille reading. The age-related pattern was similar to that of index-finger acuities, with the sighted group decreasing about $1 \%$ per year and the blind group maintaining high acuity across age.

Once again, the separation between blind and sighted data is clear, with the $95 \%$ confidence intervals on the regression lines being nonoverlapping above age 25 . For the ring finger, the variability in the blind group is greater than for the index finger, and there is less evidence of a floor effect. None of the blind subjects had perfect performance on the -0.3 line, and the overall performance level was $62.5 \%$ for the blind group on this line.

Ring-finger acuities were only slightly poorer than index-finger acuities. Using the regression lines in Figure 3 to compare values at 20 years of age, the acuities for the sighted subjects were $1.46 \mathrm{~mm}$ (index) and $1.56 \mathrm{~mm}$ (ring), and for the blind subjects, $1.21 \mathrm{~mm}$ (index) and $1.26 \mathrm{~mm}$ (ring). Vega-Bermudez and Johnson (2001) found a larger difference in acuities for the ring and index fingers for their group of 8 sighted subjects (males ranging in age from 22 to 57 years). Averaged across hands, the $71 \%$ correct grating-orientation thresholds were $1.24 \mathrm{~mm}$ for the index finger and $1.65 \mathrm{~mm}$ for the ring finger.

\section{Discussion}

Our findings on tactile acuity are consistent with other recent findings in two ways, but have one important difference. Consistent with recent findings (Dinse et al., 2006; Goldreich \& Kanics, 2003, 2006; Stevens, 1992; Stevens, Alvarez-Reeves, Dipietro, Mack, \& Green, 2003; Stevens \& Choo, 1996; Stevens \& Patterson, 1995; VegaBermudez \& Johnson, 2004), we found an age-related decline in tactile acuity on the fingertip for our normally sighted subjects. Our method for measuring tactile acuity was different from that used in the prior studies. We used a 
A Tactile Acuity on the Index Finger Versus Age

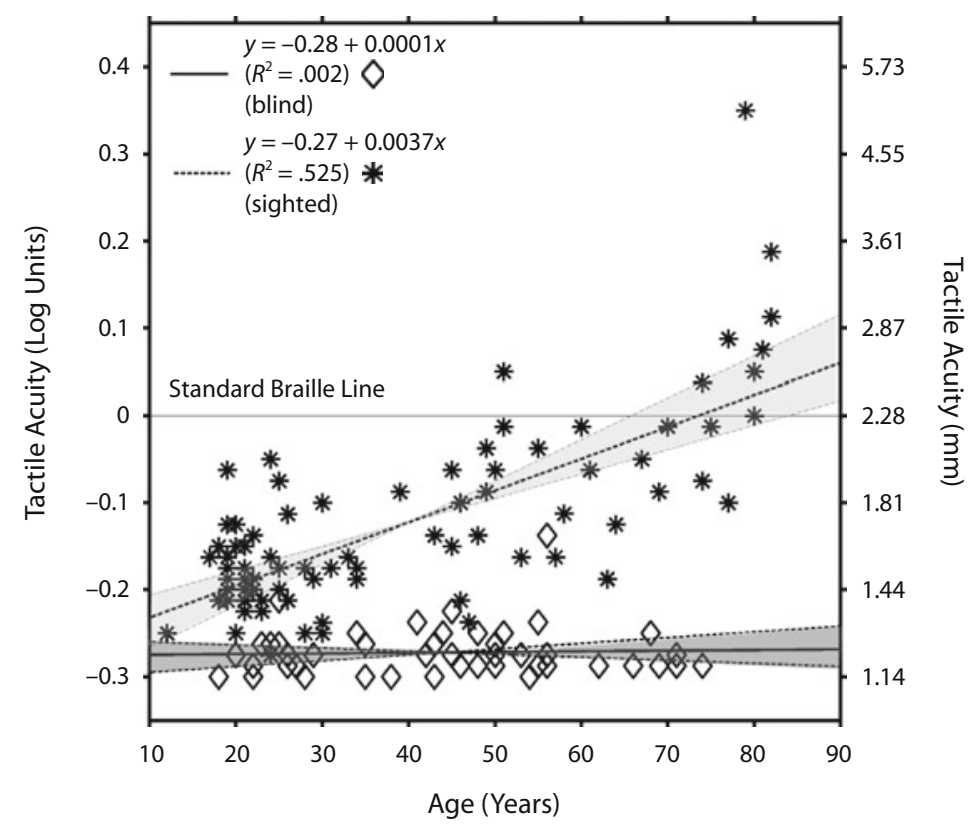

B Tactile Acuity on the Ring Finger Versus Age

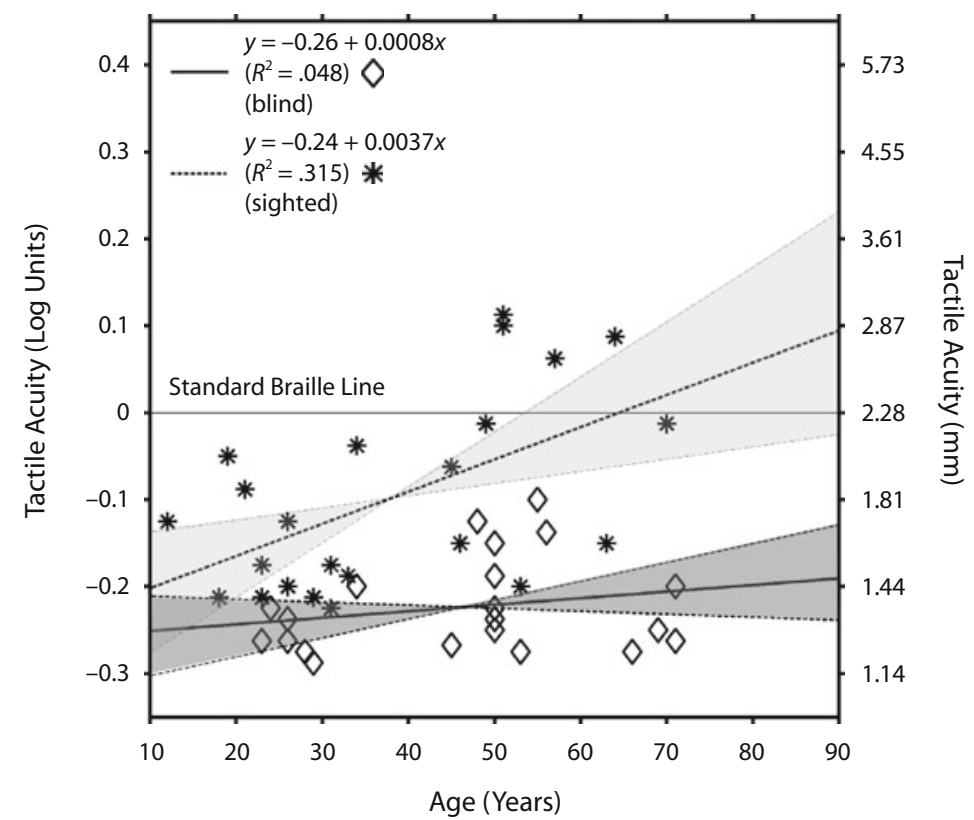

Figure 3. Tactile acuity is plotted as a function of age for blind (diamonds) and sighted (stars) subjects in Experiment 1. Measurements were obtained with the dot chart (see Figure 2) for the index finger (panel A) and the ring finger (panel B). Acuity values refer to the center-to-center separation of adjacent dots in log units (left scale) or in millimeters ( $\mathrm{mm}$; right scale). A horizontal line shows the dot separation for standard braille symbols $(0 \log$ units, $2.28 \mathrm{~mm}$ ). Also shown are regression lines (leastsquares fit; dark line for the blind subjects, dashed line for the sighted subjects) and $\mathbf{9 5 \%}$ confidence intervals determined with a resampling method as described in the Method section for blind (dark gray band) and sighted (light gray band) subjects. 
tactile-acuity chart modeled on the design of visual-acuity letter charts. The test involved the identification of braillelike symbols and permitted the subjects to actively scan the symbols without a time limit. In contrast, the other studies used passive presentation of stimuli for fixed, brief periods, and two-alternative forced choice discrimination between the presence or absence of a gap, the orientation of a tactile grating, or one versus two points. Despite these methodological differences, there is good quantitative agreement between our results for sighted subjects and those of the other studies, in terms of both the mean threshold size ( $1.72 \mathrm{~mm}$ in our study vs. 1.21 to $3.5 \mathrm{~mm}$ in previous studies) and the growth of threshold size with age $(0.86 \%$ increase per year in our study vs. $1 \%$ increase in Stevens and colleagues' studies).

Also consistent with recent findings (Goldreich \& Kanics, 2003; Stevens et al., 1996; Van Boven et al., 2000), we found that blind subjects had better tactile acuity than agematched sighted subjects. The mean tactile acuity for our 49 blind subjects was $-0.27 \log$ unit, compared with -0.12 $\log$ unit for our 83 sighted subjects. This corresponds to a mean difference in threshold dot separation of $0.50 \mathrm{~mm}$, compared with differences ranging from about 0.16 to $0.61 \mathrm{~mm}$ for the three studies cited above (see Table 1).

The important difference between our results and those of other recent studies is the retention of high tactile acuity across the life span for our blind subjects. We did not observe the age-related decline in tactile acuity for blind subjects reported by Stevens et al. (1996) and Goldreich and Kanics $(2003,2006)$. What might account for this surprising retention of tactile acuity by our blind subjects, and what are the implications? Before considering the implications, we describe Experiment 2, in which we considered two possible explanations related to the design of the tactile-acuity chart used in Experiment 1.

\section{EXPERIMENT 2 Comparing Tactile Acuity Using the Ring Chart and the Dot Chart}

A floor effect in Experiment 1 may have hidden an agerelated decline in tactile acuity among our blind subjects. Most of our blind subjects were able to identify characters on or close to the bottom line $(-0.3 \log$ unit) on the dot chart. As described in the Method section of Experiment 1, the design did not permit lines with smaller dot spacing. It is plausible that younger blind subjects could have demonstrated even better acuity if not for this floor effect, and that an age-related difference between younger and older blind subjects could have emerged. We addressed the floor effect in the design of a second type of tactile-acuity chart - the ring chart shown in Figure 2B. This chart was capable of revealing finer spatial resolution than the dot chart was.

It is also possible that the linguistic properties of the dot chart provide some unique advantage to braille readers, and that this advantage accounts for retention of acuity across age. Perhaps their familiarity with the braille-like symbols supports performance that is specific to acuity measurements on this chart. There are two reasons to doubt this. First, if linguistic familiarity heightens acuity, we might expect to find, on letter charts, unique characteristics of visual acuity that are not generalizable to other measures of visual acuity, such as Landolt $\mathrm{C}$ acuity. But it is well known that both of these types of acuity show similar dependence on most stimulus and subject variables. Second, whereas the symbols on the 0 -log-unit line of the dot chart were standard braille letters and were certainly highly familiar to our braille readers, the other symbols on the chart were not nearly as familiar. Almost all braille materials use a single size, the standard braille dimensions shown in Figure 1. Braille readers rarely encounter text in nonstandard braille sizes. ${ }^{4}$

We conducted tactile acuity measurements on blind and sighted subjects on both the dot chart and a second type of acuity chart, the ring chart (Figure 2B). We used this comparison to assess the floor effect and the possible linguistic salience of the dot chart for braille readers, and also to attempt to generalize the results from Experiment 1 to a second set of test symbols. Identification of the orientation of Landolt Cs is often considered the gold standard for visual-acuity testing (National Research Council Committee on Vision, 1980). The symbols are low in linguistic meaning and are likely to be of roughly equal salience for blind and sighted subjects. For these reasons, we designed the ring chart for testing in Experiment 2.

\begin{tabular}{|c|c|c|c|c|}
\hline & $\begin{array}{l}\text { hod } \\
\text { bjects. } \\
\text { of } 10 \text { ( } \\
66.5 \text { ye } \\
\text { ger grou } \\
\text { n age, } 7 \\
\text { four g } \\
\text { udy pro } \\
\text { utional } \\
\text { imuli. T } \\
\text { uter-cor }\end{array}$ & $\begin{array}{l}\text { e divi } \\
\text { ean ag } \\
\text {. We } \\
\text { of } 10 \text { ( } \\
\text { years) } \\
\text { ups. Al } \\
\text { col wa } \\
\text { view B } \\
\text { ring } \\
\text { olled } 3\end{array}$ & $\begin{array}{l}\text { d } 22 \mathrm{~b} \\
31.2 \text { ye } \\
\text { vided } \\
\text { ean age } \\
\text { Tables } 3 \\
\text { of the } \\
\text { approv } \\
\text { ard. } \\
\text { art wa } \\
\text { route }\end{array}$ & $\begin{array}{l}\text { nd br } \\
\text { s) an } \\
\text { norr } \\
29.3 \text {. } \\
-3 \mathrm{C} \\
\text { bject } \\
\text { by t } \\
\text { nade } \\
\text { Shop }\end{array}$ \\
\hline & Group & In Exp & & \\
\hline & Ger & & Hand & sed \\
\hline ge & Female & Male & Right & $\overline{\text { Left }}$ \\
\hline 39 & 6 & 4 & & 4 \\
\hline 81 & 8 & 4 & 6 & 6 \\
\hline 35 & 6 & 4 & 8 & 2 \\
\hline 85 & 4 & 5 & 7 & 2 \\
\hline
\end{tabular}


Table 3B

Additional Characteristics of Blind Subjects in Experiment 2

\begin{tabular}{|c|c|c|c|c|c|c|c|c|c|c|c|c|}
\hline \multirow[b]{2}{*}{ Subjects } & \multicolumn{2}{|c|}{ Vision Status } & \multicolumn{2}{|c|}{$\begin{array}{c}\text { Onset Age } \\
\text { of Low } \\
\text { Vision/ } \\
\text { Blindness }\end{array}$} & \multicolumn{2}{|c|}{$\begin{array}{c}\text { Age } \\
\text { Started } \\
\text { to Learn } \\
\text { Braille } \\
\end{array}$} & \multicolumn{3}{|c|}{$\begin{array}{c}\text { Years of } \\
\text { Braille Reading }\end{array}$} & \multicolumn{3}{|c|}{$\begin{array}{l}\text { Braille Reading } \\
\text { Speed (wpm) }\end{array}$} \\
\hline & None & Low & $M$ & $S D$ & $M$ & $S D$ & $M$ & $S D$ & Range & $M$ & $S D$ & Range \\
\hline Younger $(n=10)$ & 8 & 2 & 1.0 & 2.0 & 5.3 & 2.2 & 25.8 & 5.4 & $16-32$ & 111.1 & 26.4 & $68.2-168.3$ \\
\hline $\operatorname{Older}(n=12)$ & 9 & 3 & 1.8 & 2.9 & 5.9 & 1.1 & 61.2 & 8.8 & $48-75$ & 106.3 & 28.3 & $35.8-139.3$ \\
\hline
\end{tabular}

Note-Age statistics are measured in years.

symbol of the ring chart is the Landolt C (Windows TrueType Sloan font), presented in 0.4-mm relief, with the gap oriented in one of four directions: up, down, left, right (see Figure 2B). The chart consists of 11 rows of eight pseudorandomly oriented Cs. The sizes of the Cs decrease as the rows progress toward the bottom of the chart in 0.1 $\log$ unit. The sizes of the Cs change in proportion to the size of the gap in each row. The 0 line on the ring chart contains Cs with gaps of $2.40 \mathrm{~mm}$, nearly matched in size with the dot spacing on the dot chart $(2.28 \mathrm{~mm})$. This matching allows for plausible comparisons between numerical values of acuity measured on the two charts. The chart was designed to have three rows larger than this reference line, extending to $+0.3 \mathrm{log}$ unit (4.8-mm gap size), and seven smaller rows, extending to $-0.7 \mathrm{log}$ unit. Subsequent to manufacture of this custom chart, we directly measured the gap sizes of all symbols with a $10 \times$ reticle. We discovered two manufacturing defects at the small end of the chart. First, row -0.6 duplicated row -0.5 in gap size, and row -0.7 had the gap size we expected for row -0.6 . As a result, the true range of the chart was from $+0.3 \mathrm{log}$ unit (4.8-mm gap size) to $-0.6 \log$ unit (0.55-mm gap size). Second, we discovered that at some point during testing, two of the Cs on the bottom line of the chart were damaged, so that their gaps were enlarged. Accordingly, for scoring of the final line of the chart, we included only the six intact symbols. We took both of these defects into account in the calculation of acuity on the ring chart.

The design of the ring chart differs in three important ways from that of the dot chart. First, the ring and gap stimuli on the ring chart are uniformly scalable, whereas only the distance between dots of constant size were scalable in the dot chart. Second, smaller stimuli are included on the ring chart $(-0.6 \log$ unit, compared with -0.3 $\log$ unit for the dot chart), reducing the likelihood of a floor effect on acuity. Third, the ring stimuli on the ring chart are expected to

Table 3C

Median Tactile Acuity Scores of Four Subject Groups in Experiment 2

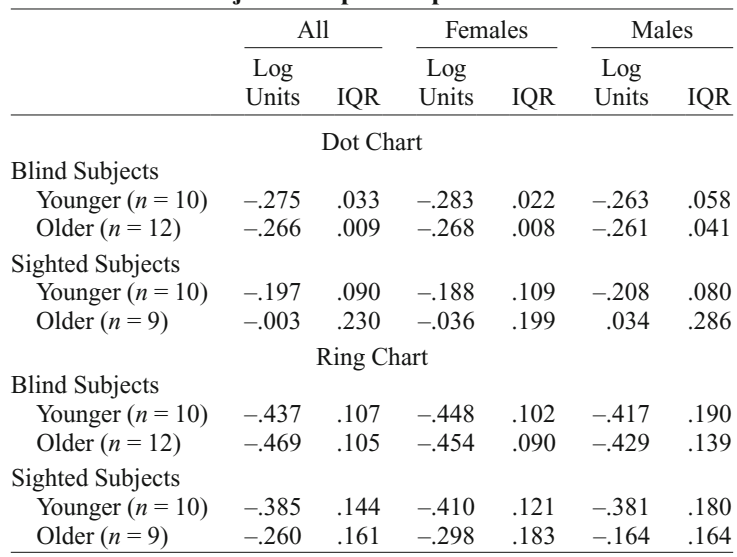

Note-IQR, interquartile range. have minimal and roughly equivalent linguistic salience for blind and sighted subjects.

The same scoring method was used for the ring chart as for the dot chart, except that errors were computed relative to the $-0.6-\log$ unit line, and corrections were made for the manufacturing defects discussed above [score $=-0.6+$ (number of errors $\times 0.0125)$ ].

Procedure. For each subject, tactile acuity was measured four times on the dot chart and four times on the ring chart. Variation in the sequence of symbols was accomplished by presenting the chart in four orientations in the four tests - normal upright orientation (with the largest symbols at the top and the smallest symbols on the bottom), $90^{\circ}$ (with the largest symbols in the left column), $180^{\circ}$ (with the largest symbols on the bottom), and $270^{\circ}$ (largest symbols in the right column). In all cases, the subject read the row (or column) containing the largest symbols first, then proceeded line by line to the smallest symbols. All four measurements were completed on one chart before testing on the second chart began. The order of chart presentation (dot or ring) alternated across subjects.

All testing was conducted on the subjects' preferred index finger, with no testing on the ring finger. For the ring chart, all subjects indicated the location of the gap for each symbol - top, bottom, left, right. Otherwise, the general features of testing were like those described for the dot chart in Experiment 1.

\section{Results}

The distributions of tactile acuities among the four groups (blind vs. sighted subjects, younger vs. older subjects) deviated significantly from normal distributions, with skewing in the direction of poorer acuity (Kolmogorov-Smirnov goodness-of-fit test, $p<.05$ ). Friedman's ANOVA on the acuity values showed that neither chart orientation nor repeated measures were significant determinants of acuity for either the dot chart $\left[\chi^{2}(3)=6.7, p=.08\right]$ or the ring chart $\left[\chi^{2}(3)=0.64, p=.89\right]$. Accordingly, the acuity values for the four orientations were averaged for each subject and each chart for use in subsequent analyses. Descriptive statistics for the four subject groups are reported as medians and interquartile ranges. For statistical analyses, the subjects' acuity values were ranked (ties averaged) and analyzed by a mixed design ANOVA to investigate the difference in tactile acuities for each group (Conover \& Iman, 1981). Figure 4 summarizes acuities of the four groups (blind, sighted; younger, older) on the dot chart and the ring chart.

A three-way ANOVA was performed on the ranked values of tactile acuity with type of chart (dot and ring) as a within-subjects variable, and vision status (blind, sighted) and age (younger, older) as between-subjects variables. There was a significant main effect of vision status $\left[F(1,74)=67.7, p<.001, \eta^{2}=.47\right]$, with the blind subjects performing better than the sighted subjects on both the dot chart (by a median of $0.17 \log$ unit) and the ring 
A

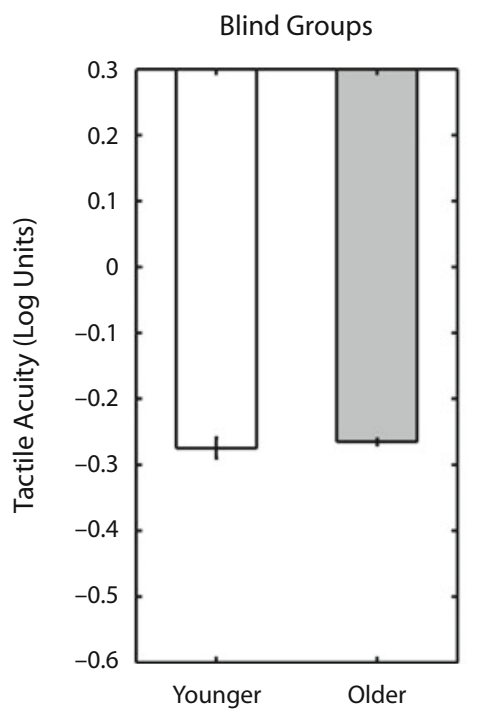

\section{Dot Chart}

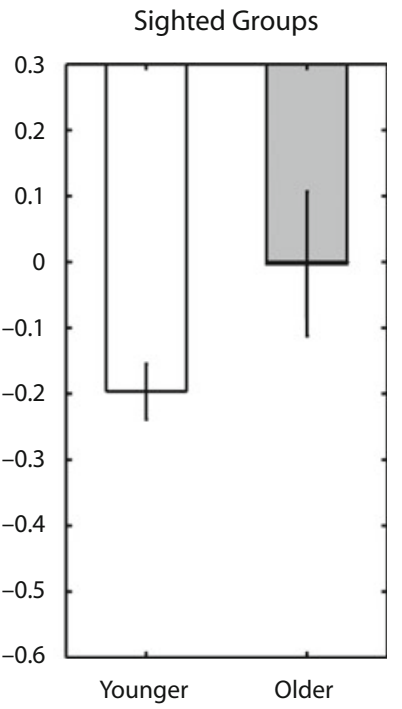

B

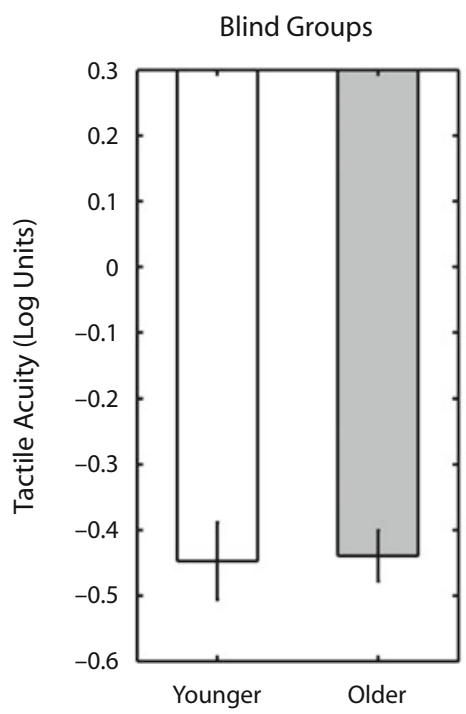

Ring Chart

Sighted Groups

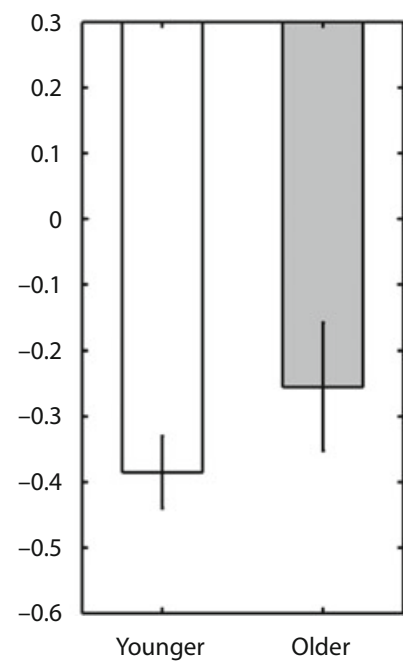

Figure 4. Median tactile acuities and error bars showing the interquartile range are shown for four groups for measurements with the dot chart (panel A) and the ring chart (panel B) in Experiment 2.

chart (by $0.09 \log$ unit). There was a significant main effect of chart type $\left[F(1,74)=155.6, p<.001, \eta^{2}=.68\right]$, with ring-chart acuity better than dot-chart acuity by a median of $0.125 \log$ unit. There was a significant main effect of age group $\left[F(1,74)=26.4, p<.001, \eta^{2}=.26\right]$, with the acuity of the younger subjects being better than that of the older subjects by a median of $0.028 \log$ unit. There was a significant interaction between age and vision status $[F(1,74)=$ $\left.15.8, p<.001, \eta^{2}=.18\right]$, reflecting a stronger effect of age on acuity for the sighted subjects than for the blind subjects. The age $\times$ vision status interaction holds for both the dot chart and the ring chart. Neither the age $\times$ chart $(p=.13)$ nor the vision status $\times$ chart $(p=.21)$ interaction was statistically significant. The three-way interaction among chart type, age, and vision status was statistically significant $\left[F(1,74)=4.31, p=.04, \eta^{2}=.06\right]$, indicating that the age $\times$ vision interaction was slightly stronger for the dot chart than for the ring chart.

Performance on the dot chart. The older sighted subjects had significantly worse tactile acuity than did the younger sighted subjects, by a median of $0.19 \log$ unit $(p=.001)$. In contrast, there was no significant difference 
between the younger (median of $-0.28 \log$ unit) and older (median of $-0.27 \log$ unit, $p=.23$ ) blind groups. The tactile acuity shown by our blind subjects in Experiment 2 was very similar to that in Experiment 1 ( $-0.27 \log$ unit).

Figure 5A plots acuity versus age for the dot chart, analogous to Figure 3A in Experiment 1. Regression lines were fit to the data for blind and sighted subjects. The pattern of results was very similar to that in Experiment 1. For the sighted subjects, there was a significant correlation between acuity and age $(p<.001)$. The regression line has a slope of $0.005 \log$ unit per year, equivalent to an increase of $1.15 \%$ per year in threshold dot spacing. This is similar to the $0.86 \%$ observed in Experiment 1 . For the blind subjects, there was a weak correlation between age and tactile acuity $\left(r_{\mathrm{s}}=.42\right)$ bordering on statistical significance $(p=.05)$. But for this group, the growth in the tactile threshold was slight $(0.12 \%$ per year; the slope of the regression line was $0.0005 \log$ unit per year).

Performance on the ring chart. One goal in designing the ring chart was to reduce or eliminate the floor effect observed with the dot chart. The symbols on the ring chart decreased to a gap size half the size of the dot spacing on the lowest line of the dot chart $(-0.6 \log$ unit on the ring chart, compared with $-0.3 \log$ unit on the dot chart). If the floor effect were entirely removed, average performance should drop to the chance level of $25 \%$ on the bottom line of the ring chart. Average performance across all subjects was $7.7 \%$ on the bottom line of the ring chart, ${ }^{5}$ and no subject scored better than $50 \%$ correct ( 3 of 6 ) on this line. Moreover, variability across subjects was higher on the ring chart (Figure 5), as expected without a floor effect. We conclude that the design of the ring chart successfully eliminated the floor effect found with the dot chart.

Figure 6 plots acuity on the ring chart versus that on the dot chart for the blind and sighted groups. Regression lines were fit to the data for blind (dark solid line) and sighted (dark dotted line) subjects. For both subject groups, there was a strong and positive correlation between acuity measured by ring and dot charts (blind group, $r=.85, p<.001$; sighted group, $r=.82, p<$ $.001)$. These strong correlations imply that the two charts measured the same aspect of cutaneous spatial resolution. Overall, acuities were better on the ring chart than on the dot chart. We will consider reasons for this difference in the Discussion section.

Similar to the results with the dot chart, our older sighted subjects had significantly worse tactile acuity than did the younger sighted subjects by a median of $0.125 \log$ unit $(p<.001)$. In contrast, there was no significant difference between the younger (median of $-0.45 \log$ unit) and older (median of $-0.44 \log$ unit, $p=.97$ ) blind groups.

Figure 5B plots acuity on the ring chart versus age for the two groups, analogous to Figure 5A for the dot chart. Regression lines were fit to the data for blind and sighted subjects. For the sighted subjects, there was a significant correlation between acuity and age, and the regression line has a slope of $0.004 \log$ unit per year, equivalent to an increase of $1.0 \%$ per year in threshold gap size for the Landolt rings, similar to the slope on the dot chart.
A major goal of Experiment 2 was to determine whether retention of tactile acuity into old age would be observed for blind subjects on a test not involving braille-like symbols. Consistent with the results on the dot chart, the blind subjects exhibited no significant effect of age on tactile acuity measured with the ring chart.

Relationship between tactile acuity and braille reading speed. The braille reading speeds of the 22 blind subjects were measured with the braille version of the MNREAD test (Legge et al., 1999). ${ }^{6}$ Their reading speeds ranged from 36 to $167 \mathrm{wpm}$ with a mean of $109 \mathrm{wpm}$. Reading speeds for the two groups - (younger, 111 \pm 26.2 wpm; older, $108 \pm 28.8 \mathrm{wpm}$ ) - were not significantly different $[t(20)=0.25, p=.80]$.

Neither braille reading speed nor tactile acuity (measured with either the dot or ring chart) differed significantly between the younger and older blind groups. There was no significant correlation between braille reading speed and tactile acuity $\left(p_{\mathrm{s}}>.70\right)$. Years of reading braille (16-75) did not correlate significantly with braille reading speed $(p=.83)$. There was a significant positive correlation between years of braille reading and tactile acuity for the dot chart $\left(r_{\mathrm{s}}=.48, p=.04\right)$, but no significant correlation for the ring chart $\left(r_{\mathrm{s}}=.28, p=.22\right)$.

\section{Discussion}

The main finding from Experiment 2 was that the surprising retention of tactile acuity in old age by blind subjects generalized from acuity measured with braille-like symbols to acuity measured with Landolt rings. Experiment 2 also showed that the lack of an age-related decline for blind subjects observed in Experiment 1 was not due to a floor effect that had been introduced by the design of the dot chart. Experiment 2 also confirmed the age-related decline in tactile acuity for sighted subjects, as well as the superiority of tactile acuity on the fingertip for blind subjects over age-matched sighted subjects.

We did not find any association between braille reading speed and tactile acuity for our blind subjects, confirming similar observations by Stevens et al. (1996). There are two reasons why this finding may not be surprising. First, our blind subjects did not exhibit an age-related loss in tactile acuity, which could potentially have resulted in an agerelated loss in braille reading speed. Second, analogous to visual reading, it may be the case that once a sufficient acuity reserve is achieved, reading speed becomes independent of acuity. In visual reading, acuity reserve refers to the separation in size between acuity letters and text letters. For normally sighted subjects, reading speed becomes independent of angular print size when text letters are two to three times larger than the acuity letter size (for a review, see Legge, 2007, chap. 3). For braille readers with adequate tactile acuity, the wide range of reading speeds is probably due to differences in nonsensory manual scanning strategies and cognitive or linguistic capabilities (Millar, 1997).

Before turning to the General Discussion, we comment on the acuity differences between the two charts. Acuities measured on the ring chart were better than those measured on the dot chart by a median of $0.125 \log$ unit $(p<$ 

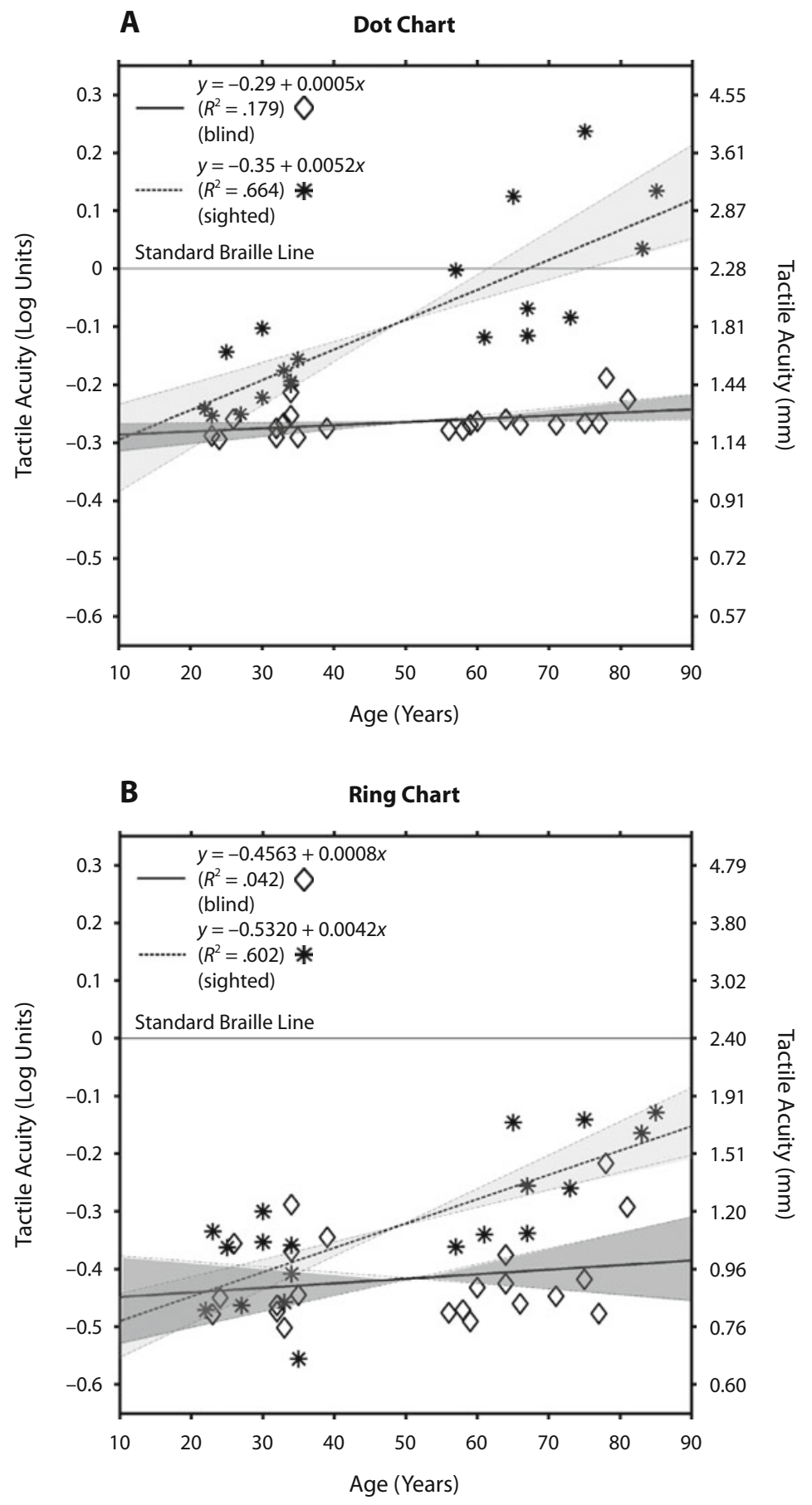

Figure 5. Tactile acuity on the index finger is plotted as a function of age for blind and sighted subjects in Experiment 2. Measurements were obtained with the dot chart (panel A) and the ring chart (panel B). Acuity values refer to the center-to-center separation of adjacent dots or the size of the gap in the Landolt rings, in log units (left scale) or in milimeters ( $\mathrm{mm}$; right scale). Data are shown for 22 blind (diamonds) and 19 sighted (stars) subjects. Also shown are least-squares regression lines (dark for blind, dashed for sighted) and $95 \%$ confidence intervals determined with a resampling method as described in Experiment 1 (dark gray band for blind, light gray band for sighted). 


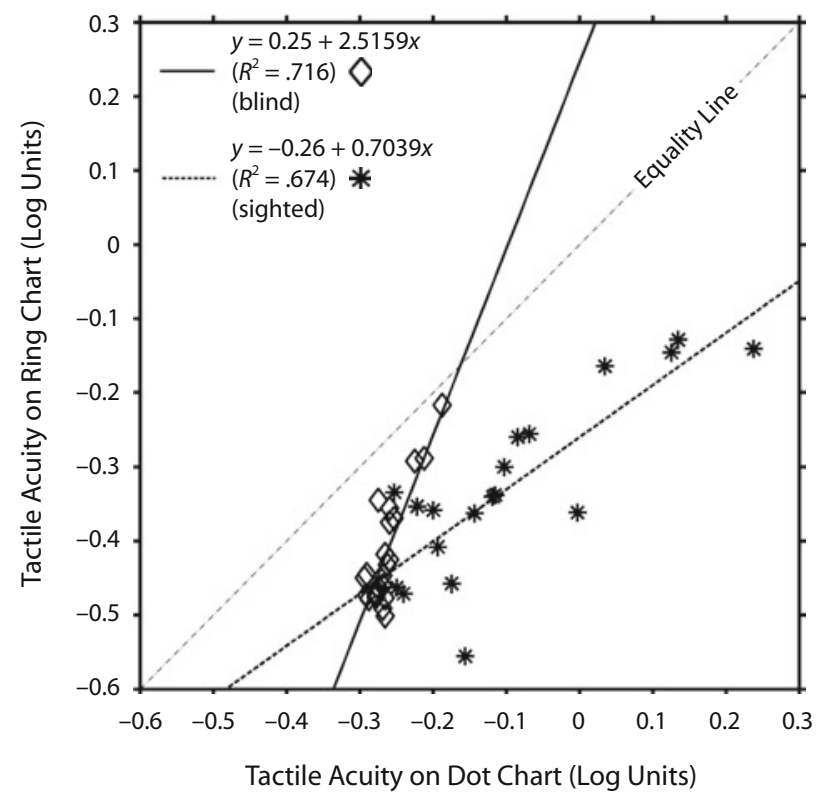

Figure 6. Tactile acuity measured on the ring chart is plotted against tactile acuity measured on the dot chart for 22 blind (diamonds) and 19 sighted (stars) subjects in Experiment 2. Acuity values in log units refer to the size of the gap in the Landolt rings (vertical axis) and the center-tocenter separation of adjacent dots in the dot chart (horizontal axis). The gray dashed line is the equality line, showing what would be expected if tactile acuities measured on the two charts were the same.

\begin{tabular}{|c|c|c|c|c|}
\hline \multicolumn{2}{|c|}{ Size } & \multirow{2}{*}{ Dot Symbols } & \multirow{2}{*}{ Landolt C } & \multirow{3}{*}{$\underset{\text { scale bar }}{5 \overrightarrow{\mathrm{mm}}}$} \\
\hline (Log Unit) & $(\mathrm{mm})$ & & & \\
\hline 0.3 & 4.55 & $\therefore$ & & \\
\hline 0.2 & 3.61 & $\because$ & & \\
\hline 0.1 & 2.87 & : & & \\
\hline 0.0 & 2.28 & s* & ) & \\
\hline-0.1 & 1.81 & 7 & C & \\
\hline-0.2 & 1.44 & $\Delta$ & 0 & \\
\hline-0.3 & 1.14 & 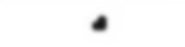 & م & \\
\hline-0.4 & 0.91 & $\bullet$ & 0 & \\
\hline-0.5 & 0.72 & $\bullet$ & 0 & \\
\hline
\end{tabular}

Figure 7. Low-pass-filtered (blurred) images are shown for dot symbols and Landolt $C$ symbols for a range of sizes, as indicated on the left. The filter, proposed by Loomis, had a 2-D Gaussian impulse response function with full width at a half amplitude of $5.88 \mathrm{~mm}$ and is thought to represent the intrinsic spatial filtering of cutaneous processing on the fingertip (Loomis, 1981; Loomis \& Lederman, 1986). 
.001). Undoubtedly, one reason for the chart difference is that elimination of the floor effect on the ring chart allowed many subjects to achieve better acuities than could be measured on the dot chart.

In seeming contradiction to the difference we found on the two charts, it is generally understood that braille letters are more legible than size-matched, embossed roman letters. Loomis (1981) demonstrated this difference experimentally. He explained the difference by hypothesizing that (1) tactile letter recognition includes a distal stage of low-pass, spatial-frequency filtering; (2) the lowfrequency content of braille letters is more varied than the low-frequency content of roman letters; and (3) following low-pass filtering, braille letters would therefore be more discriminable than roman letters. Our dot and ring charts did not contain matched sets of braille and roman letters, so this analysis was not directly applicable. Nevertheless, it is interesting to consider how Loomis's proposed low-pass filtering could affect the legibility of the symbols on the dot and ring charts. In Figure 7, we illustrate the effects of low-pass filtering on dot and ring stimuli of different sizes, using Loomis's filter (Loomis, 1981; Loomis \& Lederman, 1986). These blurred images provide a plausible rendering of the information available in the corresponding tactile stimuli and confirm the usefulness of Loomis's proposed filter. (Keep in mind that Loomis derived his proposed filter from measurements on younger adults using passive touch.)

Consistent with our data, it is evident from Figure 7 that legibility survives to a nominally smaller size for the ring stimuli. Two attributes of the stimuli contribute to this difference. First, spacing for the dot stimuli is defined as center-to-center dot spacing rather than edge-to-edge dot spacing. By comparison, spacing for the ring stimuli is defined as the edge-to-edge gap width. This difference tends to penalize performance on the dot stimuli relative to that on the ring stimuli. Second, when the dot symbols get smaller, the spacing diminishes, but not the dot size per se. For the smaller symbols (i.e., dot stimuli $\leq$ $-0.3-\log$ unit line), the large dots begin to overlap, contributing to reduced legibility. By comparison, the ring stimuli scale in size so that there is always an explicit gap present. The numerical differences in the acuity measurements on the two charts are undoubtedly influenced by these design factors. For this reason, we do not believe that the between-charts acuity differences are likely to be of importance in our understanding of the underlying perceptual limitations.

\section{GENERAL DISCUSSION}

In the introduction, we summarized recent findings of tactile acuity thresholds for younger and older subjects, and blind and sighted subjects (Table 1). Table 4 summarizes corresponding findings from our two experiments for tactile acuities.

The main finding of this study is that tactile acuity on the fingertip does not exhibit an age-related decline in old age for blind braille readers, whereas sighted subjects show the previously observed age-related decline. Con-
Table 4

Summary of Tactile Acuities for 20- and 80-Year-Old Subjects

\begin{tabular}{l} 
for 20- and 80-Year-Old Subjects \\
\cline { 2 - 3 } \cline { 4 - 5 } \\
\cline { 2 - 5 }
\end{tabular}

\begin{tabular}{|c|c|c|c|c|}
\hline \multicolumn{5}{|c|}{ Experiment 1} \\
\hline Dot Chart & & & & \\
\hline Log units & -0.280 & -0.270 & -0.190 & 0.030 \\
\hline Dot separation & 1.20 & 1.22 & 1.46 & 2.43 \\
\hline \multicolumn{5}{|c|}{ Experiment 2} \\
\hline \multicolumn{5}{|l|}{ Dot Chart } \\
\hline Log units & -0.280 & -0.250 & -0.250 & 0.028 \\
\hline Dot separation & 1.26 & 1.35 & 1.36 & 2.56 \\
\hline \multicolumn{5}{|l|}{ Ring Chart } \\
\hline Log units & -0.440 & -0.390 & -0.450 & -0.200 \\
\hline Gap size & 0.87 & 0.97 & 0.86 & 1.53 \\
\hline
\end{tabular}

Note-Dot separations and gap sizes are expressed in millimeters. The values for Experiment 1 and Experiment 2 are taken from the regression lines in Figure 3 and Figure 6, respectively.

stancy of tactile acuity across age for blind subjects was demonstrated in Experiment 1 on an acuity chart with braille-like dot patterns. Experiment 1 also demonstrated that the effect transferred to the ring finger, which is not normally used for braille reading. In Experiment 2, the constancy of tactile acuity across age in blind subjects generalized to measurements of acuity with a ring chart.

These results pose a puzzle. Why did we observe retention of tactile acuity across age with blind subjects, whereas other investigators have observed an age-related decline (Goldreich \& Kanics, 2003, 2006; Stevens et al., 1996)? We cannot be sure of the reason for the discrepancy, but we now consider one possibility.

\section{Active and Passive Tactile Acuity}

Our study used active touch, whereas most recent studies of tactile acuity have used passive touch with controlled contact force and stimulus duration. In their studies of the age dependence of tactile acuity in blind subjects, Stevens et al. (1996) and Goldreich and Kanics (2003) presented stimuli for controlled periods to a static (passive) fingertip. In our experiments, subjects freely and actively scanned the dot patterns and Landolt Cs in the acuity tests. Are there any reasons to believe that active and passive measurements of tactile acuity have different properties?

Gibson (1962) used the concept of active touch to describe the exploration of felt objects, distinguishing it from passive touch. Passive touch refers to perception from cutaneous signals that result from tactile stimulation of a passive observer. In contrast, active touch includes both bottom-up tactile stimulation and kinesthetic signals from motor movements of the hands or fingers. Active touch also includes purposive action (i.e., what we might term top-down or attention-driven tactile exploration). Gibson made the analogy to vision: "These touching movements of the fingers are like the movements of the eyes. In fact, active touch can be termed tactile scanning, by analogy with ocular scanning" (p. 477). Millar (1997) argued for the importance of active touch in understanding braille 
reading. She has made the case that active touch is fundamentally intersensory, involving more than tactile input. The differences in information available during active and passive fingertouch can be understood by considering the following four cases, three of them passive and one active.

In the first case, a static stimulus is presented to the static finger for a fixed duration. This is the prototypical passive touch being used in most recent studies of tactile acuity.

A time-varying stimulus is presented to the static finger in the second case, which is also considered to be passive touch. The temporal profile of stimulation can affect tactile perception, distinct from the active or passive nature of the stimulation. For instance, Cascio and Sathian (2001) have shown that perceived roughness of gratings depends on the temporal frequency of presentation to the passive finger. Vega-Bermudez, Johnson, and Hsaio (1991) have studied the effect on tactile letter recognition of the velocity of stimulus scans across the passive fingertip (for further discussion of this study, see below).

The experimenter moves the subject's passive finger over a 2-D or 3-D shape. In this third case, the subject receives kinesthetic feedback from the finger movements, but does not issue the motor commands or plan the finger's trajectory. Because the subject lacks control over the movement, this form of stimulation is also considered passive (Loomis \& Lederman, 1984).

In active touch, the subject plans and executes finger movements to explore the target of interest, typically with the goal of making a judgment through active informationseeking. In this fourth case, the subject receives tactile and kinesthetic input and can invoke a strategy for tactile exploration suitable for the goal in question (Lederman \& Klatzky, 1987). For acuity judgments or other fine discriminations, active touch also permits the subject to bring the most sensitive portion of the finger pad in contact with the target.

Loomis and Lederman (1984) summarized findings with these distinctions in mind and found little compelling evidence for a performance advantage for active over passive touch. Grunwald (1966) compared braille reading speed when subjects moved their hands across lines of static text (active touch) and when an "endless line" of text moved past their stationary fingers (passive touch). Reading speed was slightly faster in the passive case, probably because of the time saved in not needing to return the fingers to the left margin after each line was read.

Some subsequent findings, however, have revealed performance advantages for active touch. Heller (1986) tested tactile pattern recognition for normally sighted college students. The stimuli were the 26 braille characters of the alphabet. A subject felt the character for $15 \mathrm{sec}$ and then responded by matching it to a visual representation of the characters. Subjects were tested with active touch (free movement of the finger over the static character), passive touch with a static presentation of the character to the finger, and passive touch with the character moved either horizontally or vertically back and forth across the static finger. Accuracy was higher for the active condi- tion than for the other conditions and higher for the horizontally and vertically moving presentations than for the static presentation.

Loomis (1985) has shown that there is an increasing advantage for active over passive touch for the identification of tactile letters as the relief height decreases. For letters with the relief height of braille dots (approximately $0.4 \mathrm{~mm}$ ), Loomis (1985) found that identification accuracy was $35 \%$ better for active than for passive touch.

There is recent neural evidence for distinct sensory processing of active and passive touch. Krupa, Wiest, Shuler, Laubach, and Nicolelis (2004) found different patterns of response to similar whisker stimulation in rat somatosensory area S1 during active and passive tactile stimulation. The differences could not be accounted for by bottom-up effects, implying the involvement of top-down signals in the sensory processing of active touch. Ferezou, Bolea, and Petersen (2006) observed different patterns of response in the barrel cortex of awake behaving mice compared with passive stimulation of the whiskers of awake behaving mice. There is also evidence for movement-related attenuation of cutaneous inputs from human sensory evoked potentials and animal electrophysiology (Chapman, 1994). This gating behavior could be expected to yield poorer discrimination performance for active touch, but see Chapman for a review of several mitigating factors.

Vega-Bermudez et al. (1991) measured accuracy of tactile letter recognition for sighted subjects, as a function of the velocity of lateral stimulus scans across a passive finger. They compared performance with this type of passive touch to performance when the subjects actively scanned the letters with their own finger movements. Accuracy was no better during the active scanning than during the passive scanning. This lack of a difference, however, does not exclude the possibility that experience with active tactile scanning by blind subjects could result in modified neural representations for active touch.

Vega-Bermudez et al. (1991) found that the accuracy for tactile letter recognition was constant for rates of lateral scanning of stimuli across the fingertip from 20 to $40 \mathrm{~mm} / \mathrm{sec}$, but accuracy declined for a scanning rate of $80 \mathrm{~mm} / \mathrm{sec}$. Legge et al. (1999) found that the median braille reading speed for a group of 44 experienced braille readers was 7.5 characters/sec, equivalent to $47.6 \mathrm{~mm} / \mathrm{sec}$ (the centerto-center spacing between standard braille characters is $6.35 \mathrm{~mm}$ ). Although perhaps a coincidence, the agreement between the median scanning rate for braille readers and the limiting scanning rate found by Vega-Bermudez et al. (1991) indicates that a temporal processing limit might place a boundary on braille reading speed - a velocity of approximately $50 \mathrm{~mm} / \mathrm{sec}$ on the finger, corresponding to an exposure time of $130 \mathrm{msec} / \mathrm{character}$ on the fingertip.

These considerations appear to indicate that active touch is qualitatively different from passive touch and that it exhibits qualitative differences in the age dependence of tactile acuity or other properties. The active-passive distinction appears to be the most salient difference between our method for measuring tactile acuity and the methods used by Stevens et al. (1996) and Goldreich and Kanics 
(2003) and is, hence, the most likely suspect to account for the important difference in results.

If this interpretation is correct, it remains to be determined what aspect of active touch protects tactile acuity in blind subjects from an age-related decline. One possibility pertains to the kinesthetic information. Blind subjects may learn effective motor strategies for collecting information about fine tactile features, and these strategies may offset a concomitant sensory decline. For instance, blind subjects may learn how to accumulate noisy information across repeated touches, analogous to probability summation across time in visual contrast detection (see Legge, 1978). A second possibility pertains to the quality of tactile input. Blind subjects may be more adept at learning to use the most sensitive portion of the finger pad for fine tactile discrimination. This could be especially helpful if the age-related decline in sensitivity across the finger is not uniform, with some small patches retaining high acuity longer than others.

\section{The Role of Experience}

What aspects of the lives of our blind subjects account for their advantage in tactile acuity and the age-related retention of active tactile acuity? Is it the prolonged experience with braille reading? Probably not. From our findings and those of Stevens et al. (1996), there is little or no association between braille reading speed and tactile acuity. Similar to Goldreich and Kanics (2003, 2006), we did not find a significant correlation between the tactile acuity of our blind subjects and either the age at which braille was learned or the amount of daily or weekly reading. And we found only a weak correlation between tactile acuity and the number of years reading braille. Moreover, Goldreich and Kanics $(2003,2006)$ found that even blind subjects who did not read braille had tactile acuity superior to that of age-matched sighted subjects.

Is the lack of a close link between tactile acuity and braille reading surprising? Proficient braille reading requires the ability to recognize braille characters. But we presume that these characters are sufficiently above the tactile acuity limit in size. Proficient braille reading also requires adoption of appropriate scanning strategies with the fingers and two hands (Millar, 1997). Undoubtedly, adoption of these strategies enhances braille reading speed, analogous to the skilled use of eye movements in visual reading, but it is not apparent that these strategies enhance tactile acuity. Appealing to analogies with print reading, for normally sighted individuals, enhanced visual acuity is not associated with age of learning to read print, number of years of reading, or the number of hours per day of reading. On the contrary, it has been argued that visual reading during the early school years contributes to the phenomenon of school myopia, which, at least for distance viewing, reduces visual acuity (Wallman \& Winawer, 2004).

Goldreich and Kanics (2003) favor the view that blindness per se, rather than enriched tactile experience, promotes enhanced tactile acuity. But a recent study by Ragert, Schmidt, Altenmüller, and Dinse (2004) suggests that enriched tactile experience in sighted people is associated with superior tactile acuity. Ragert et al. demonstrated that a group of younger (21-27 years of age) sighted professional pianists had tactile acuity superior to that of an age-matched group of nonmusicians. This difference was probably due to the enriched tactile experience of the pianists, although it is possible that the pianists became successful musicians because of preexisting superior tactile acuity. Two recent studies showed that sighted subjects blindfolded all day for 5 days (Kauffman, Théoret, \& Pascual-Leone, 2002) or for 90 min (Facchini \& Aglioti, 2003) exhibited reversible passive tactile-acuity gains. It remains unclear whether superiority of tactile acuity in blind subjects is due to visual deprivation, enriched tactile experience, or both.

It should be noted that we did not find a significant correlation between duration of blindness and tactile acuity (Experiment 1). But our subjects had been blind for years (average of 34.8 years), so there was ample opportunity for blindness-related changes in tactile acuity to occur.

What type of tactile experience (not specific to braille) could differ between blind and sighted people? Blind people rely on tactile shape or texture discrimination to make many daily decisions for which sighted people generally rely on vision, such as distinguishing among coins or keys, aligning the cap on a childproof pill container, or finding clothing by fabric texture. Sighted people handle and touch all the objects in these tasks, but are rarely required to focus their attention on the tactile attributes necessary to make the discrimination. Many laboratory studies have shown that attention to stimulus attributes promotes improved perceptual discrimination as represented by psychophysical threshold performance (see, e.g., Ahissar \& Hochstein, 1993) or as evidenced in the nature of the response or representation in the sensory cortex (Hsiao, O’Shaughnessy, \& Johnson, 1993; Polley, Steinberg, \& Merzenich, 2006). Braille reading may not press blind people to their tactile discrimination thresholds, but many other daily tasks probably do. Focused attention on myriad such tasks over a prolonged period could result in enhanced tactile acuity and potentially protect tactile acuity against age-related decline. In brief, the proposal here is that blind people's active touch, often compelled by necessity to operate near the threshold for detection or discrimination, contributes to both enhanced tactile acuity and protection of tactile acuity against agerelated decline.

\section{Enhanced Tactile Acuity in the Blind: Is It Central or Peripheral?}

It is generally agreed that spatial tactile resolution on the fingertip and elsewhere on the body is limited by the neural innervation density and spacing of the SAI mechanoreceptors (Craig \& Lyle, 2001, 2002; Johnson \& Hsiao, 1992). What is the anatomical basis of the age-related decline in tactile acuity on the fingertip for normally sighted subjects and that of the superior tactile acuity of blind subjects? It is plausible to seek explanations in terms of integrity of physiological structures at the fingertip it- 
self. But several plausible peripheral explanations for the age-related decline have been largely eliminated. These include physical wear and tear on the fingertip (Stevens et al., 2003), decreased cutaneous blood flow (Stevens et al., 2003), and decreased conformance (pliability) of the skin (Vega-Bermudez \& Johnson, 2004). Given that these peripheral factors do not account for the age-related decline in the tactile acuity of sighted people, it does not seem plausible for them to account for the preserved active tactile acuity of the blind. Our finding that tactile acuity is preserved on both the ring finger and the primary reading finger of braille readers (Experiment 1) also argues against an explanation specific to the mechanical properties of the fingertip.

If peripheral factors do not account for the privileged qualities of tactile acuity in blind subjects, what are the plausible central sites? Enlarged evoked potentials from the somatosensory cortex have been reported for stimulation of the braille-reading index finger of blind subjects, in comparison with the contralateral index finger (PascualLeone \& Torres, 1993). The apparent finger specificity of this effect would not account for our observation of a transfer of preserved tactile acuity to the nonreading ring finger in blind subjects (Experiment 1). Nor would it account for the lack of relationship between tactile acuity and the history or daily amount of braille reading. Other authors have proposed that the enlarged representation of the primary braille reading finger in area S1 of the somatosensory cortex might be due to the development of extra connections with the motor cortex associated with the sensorimotor aspects of braille reading, rather than enhanced tactile perception (Goldreich \& Kanics, 2003; Millar, 1997).

Evidence for activation of the visual cortex in blind subjects by tactile stimulation (Buchel, Price, Frackowiak, \& Friston, 1998; Burton et al., 2002; Cohen et al., 1997; Sadato et al., 1996) raises the question of the functional significance of this cross-modal activation. Disruption of the visual cortex in blind people by transcranial magnetic stimulation impairs performance on both braille reading and tactile identification of raised roman letters (Cohen et al., 1997). These authors proposed that recruitment of the visual cortex for tactile analysis in blind subjects might account for their superior tactile perception. Subsequent studies have revealed that short-term blindfolding of normally sighted subjects (on the order of hours or days) is accompanied by increased involvement of visual areas (including primary visual cortex V1) in the neural processing of tactile stimuli (Merabet et al., 2007; Weisser, Stilla, Peltier, Hu, \& Sathian, 2005). Although we do not yet have a firm link between characteristics of tactile processing in the visual cortex of blind people and their enhanced and preserved tactile acuity, the findings do point to the visual cortex as a plausible site for the extra neural resources.

\section{Implications for Reading Braille}

Younger sighted and younger blind subjects both have tactile acuities that permit identification of patterns smaller than braille letters by a factor of nearly 2 . By analogy to visual reading, it is likely that some acuity reserve is necessary for good reading, although the size of the acuity reserve for braille reading is unknown. Blind braille readers retain high tactile acuity throughout their lifetime. Barring interference from health problems affecting the hands or fingers, they can expect to continue proficient braille reading into old age.

The age-related loss in tactile acuity among sighted subjects inexorably reduces the acuity reserve relative to standard braille characters. According to the regression line in Figure 3A, by age 74, the acuity reserve for the sighted subjects has shrunk to zero (i.e., braille letters are at the acuity limit of $0 \log$ units). By this age, the requisite acuity reserve for skilled braille reading has likely long since been depleted, threatening any possibility of learning to read braille fluently. The majority of people in developed countries who are blind or who have severe low vision acquire their condition late in life from age-related forms of eye disease. It is this large group of late-blind individuals who are at risk for being unable to learn braille because of their age-related loss of tactile acuity.

It remains possible that some form of tactile training might restore some of the lost acuity (Dinse et al., 2006). There is evidence that the blindfolding of younger sighted subjects over a period of 5 days improved performance in tactile discrimination (Kauffman et al., 2002). It remains to be learned whether remedial training could be effective in enhancing tactile acuity in late-blinded individuals and whether such enhancement would facilitate learning to read braille.

The blind poet Stephen Kuusisto (1999, para. 20), sensing the challenge of learning braille in midlife and the relevance of high-level processes, wrote that "to learn braille in your 40's you must refresh the very infancy of touching and recharge your hands. Braille can't be learned like Berlitz Spanish. You have to think with your skin." The agerelated loss in tactile letter acuity reported in this article and the corresponding reduction in the acuity reserve may explain why late-blinded individuals are rarely successful in learning to read braille.

\section{AUTHOR NOTE}

This work was supported by NIH Grant EY002934 to G.E.L. We thank Merv Bergman for his help in producing the dot chart, Jim Williams for help in producing the ring chart, Denis Pelli for supplying us with the image file of the Landolt C, Paul Beckmann for supplying the reticle, Steve Mansfield and Paul Schrater for helpful comments and assisting with data analysis, and Daniel Goldreich for providing data from Goldreich and Kanics (2003). Thanks also to Michelle Wirth and Chris Beckmann for assistance with data collection, and to the many subjects who gave their time and insight to the study. A preliminary report on the results of Experiment 1 was given at the 1998 Association for Research in Vision and Ophthalmology annual meeting (Madison \& Legge, 1998). Correspondence concerning this article should be addressed to G. E. Legge, Minnesota Laboratory for Low-Vision Research, Department of Psychology, University of Minnesota, 75 E. River Rd., Minneapolis, MN 55455 (e-mail: legge@umn.edu).

$$
\text { Note-Accepted by the editorial board }
$$
of Editor-Elect Jeremy M. Wolfe. 


\section{REFERENCES}

Ahissar, M., \& Hochstein, S. (1993). Attentional control of early perceptual learning. Proceedings of the National Academy of Sciences, 90, 5718-5722.

Buchel, C., Price, C., Frackowiak, R. S., \& Friston, K. (1998). Different activation patterns in the visual cortex of late and congenitally blind subjects. Brain, 121, 409-419.

Burton, H., Snyder, A. Z., Conturo, T. E., Akbudak, E., Ollinger, J. M., \& Raichle, M. E. (2002). Adaptive changes in early and late blind: A fMRI study of braille reading. Journal of Neurophysiology, 87, 589-607.

Cascio, C. J., \& Sathian, K. (2001). Temporal cues contribute to tactile perception of roughness. Journal of Neuroscience, 21, 5289-5296.

Chapman, C. E. (1994). Active versus passive touch: Factors influencing the transmission of somatosensory signals to primary somatosensory cortex. Canadian Journal of Physiology \& Pharmacology, $\mathbf{7 2}$ 558-570.

Cohen, L. G., Celnik, P., Pascual-Leone, A., Corwell, B., Faiz, L., Dambrosia, J., ET AL. (1997). Functional relevance of cross-modal plasticity in blind humans. Nature, 389, 180-183.

Conover, W. J., \& Iman, R. L. (1981). Rank transformations as a bridge between parametric and nonparametric statistics. American Statistician, 35, 124-129.

Craig, J. C., \& Johnson, K. O. (2000). The two-point threshold: Not a measure of tactile spatial resolution. Current Directions in Psychological Science, 9, 29-32.

Craig, J. C., \& Lyle, K. B. (2001). A comparison of tactile spatial sensitivity on the palm and fingerpad. Perception \& Psychophysics, 6, 337-347.

Craig, J. C., \& Lyle, K. B. (2002). A correction and a comment on Craig and Lyle (2001). Perception \& Psychophysics, 64, 504-506.

Dinse, H. R., Kleibel, N., Kalisch, T., Ragert, P., Wilimzig, C., \& Tegenthoff, M. (2006). Tactile coactivation resets age-related decline of human tactile discrimination. Annals of Neurology, 60, 88-94.

EFron, B., \& Tibshirani, R. J. (1993). An introduction to the bootstrap. New York: Chapman \& Hall.

Facchini, S., \& Aglioti, S. M. (2003). Short term light deprivation increases tactile spatial acuity in humans. Neurology, 60, 1998-1999.

Ferezou, I., Bolea, S., \& Petersen, C. C. H. (2006). Visualizing the cortical representation of whisker touch: Voltage-sensitive dye imaging in freely moving mice. Neuron, 50, 617-629.

Ferris, F. L., III, Kassoff, A., Bresnick, G. H., \& Bailey, I. (1982) New visual acuity charts for clinical research. American Journal of Ophthalmology, 94, 91-96.

Gibson, J. J. (1962). Observations on active touch. Psychological Review, 69, 477-491.

GoldreICH, D., \& Kanics, I. M. (2003). Tactile acuity is enhanced in blindness. Journal of Neuroscience, 23, 3439-3445.

Goldreich, D., \& KAnics, I. M. (2006). Performance of blind and sighted humans on a tactile grating detection task. Perception \& Psychophysics, 68, 1363-1371.

Grant, A. C., Thiagarajah, M. C., \& Sathian, K. (2000). Tactile perception in blind Braille readers: A psychophysical study of acuity and hyperacuity using gratings and dot patterns. Perception \& Psychophysics, 62, 301-312.

Grunwald, A. P. (1966). A braille-reading machine. Science, 154 144-146.

Heller, M. A. (1986). Active and passive braille recognition. Bulletin of the Psychonomic Society, 24, 201-202.

Hollins, M. (1989). Understanding blindness: An integrative approach. Hillsdale, NJ: Erlbaum.

Hsiao, S. S., O’Shaughnessy, D. M., \& Johnson, K. O. (1993). Effects of selective attention on spatial form processing in monkey primary and secondary somatosensory cortex. Journal of Neurophysiology, 70, 444-447.

Johnson, K. O., \& HsiaO, S. S. (1992). Neural mechanisms of tactual form and texture perception. Annual Review of Neuroscience, $\mathbf{1 5}$, 227-250.

Johnson, K. O., \& Phillips, J. R. (1981). Tactile spatial resolution. I. Two-point discrimination, gap detection, grating resolution, and letter recognition. Journal of Neurophysiology, 46, 1177-1192.
Kauffman, T., Théoret, H., \& Pascual-Leone, A. (2002). Braille character discrimination in blindfolded human subjects. NeuroReport, 13, 571-574.

Krupa, D. J., Wiest, M. C., Shuler, M. G., Laubach, M., \& NicoleLIS, M. A. L. (2004). Layer-specific somatosensory cortical activation during active tactile discrimination. Science, 304, 1989-1992.

KuUsisto, S. (1999, March 21). Lives: In the dark. New York Times. Retreived February 1, 2008, from www.nytimes.com/ref/membercenter/ nytarchive.html.

Lederman, S. J., \& KlatzKy, R. L. (1987). Hand movements: A window into haptic object recognition. Cognitive Psychology, 19, 342-368.

LEGGE, G. E. (1978). Sustained and transient mechanisms in human vision: Temporal and spatial properties. Vision Research, 18, 69-81.

LEGGE, G. E. (2007). Psychophysics of reading in normal and low vision. Mahwah, NJ: Erlbaum.

Legge, G. E., Madison, C. M., \& Mansfield, J. S. (1999). Measuring Braille reading speed with the MNREAD test. Visual Impairment Research, 1, 131-145.

Loomis, J. M. (1981). On the tangibility of letters and braille. Perception \& Psychophysics, 29, 37-46.

Loomis, J. M. (1985). Tactile recognition of raised characters: A parametric study. Bulletin of the Psychonomic Society, 23, 18-20.

Loomis, J. M., \& Lederman, S. J. (1984, November). What utility is there in distinguishing between active and passive touch? Paper presented at the 25th Annual Meeting of the Psychonomic Society, San Antonio, TX.

Loomis, J. M., \& Lederman, S. J. (1986). Tactual perception. In K. R. Boff, L. Kaufman, \& J. P. Thomas (Eds.), Handbook of perception and human performance: Vol. 2. Cognitive processes and performance (pp. 1-41). New York: Wiley.

Madison, C. M., \& LegGe, G. E. (1998). Tactile acuity in Braille and non-Braille readers. Investigative Ophthalmology \& Visual Science (Suppl.), 39, 175

Merabet, L. B., Swisher, J. D., McMains, S. A., Halko, M. A., Amedi, A., Pascual-Leone, A., \& Somers, D. C. (2007). Combined activation and deactivation of visual cortex during tactile sensory processing. Journal of Neurophysiology, 97, 1633-1641.

Millar, S. (1997). Reading by touch. London: Routledge.

National Research Council Committee on Vision (1980). Recommended standard procedures for the clinical measurement of and specification of visual acuity. Advances in Ophthalmology, 41, 103148.

Nolan, C. Y., \& Kederis, C. J. (1969). Perceptual factors in Braille word recognition. New York: American Foundation for the Blind.

Pascual-Leone, A., \& Torres, F. (1993). Plasticity of the sensorimotor cortex representation of the reading finger in Braille readers. Brain, 116, 39-52.

Polley, D. B., Steinberg, E. E., \& Merzenich, M. M. (2006). Perceptual learning directs auditory cortical map reorganization through top-down influences. Journal of Neuroscience, 26, 4970-4982.

Ragert, P., Schmidt, A., Altenmüller, E., \& Dinse, H. R. (2004). Superior tactile performance and learning in professional pianists: Evidence for meta-plasticity in musicians. European Journal of Neuroscience, 19, 473-478.

Sadato, N., Pascual-Leone, A., Grafmani, J., Ibañez, V., Deiber, M.-P., Dold, G., \& Hallett, M. (1996). Activation of the primary visual cortex by Braille reading in blind subjects. Nature, 380, 526-528.

Stevens, J. C. (1992). Aging and spatial acuity of touch. Journal of Gerontology, 47, P35-P40.

Stevens, J. C., Alvarez-Reeves, M., Dipietro, L., Mack, G. W., \& Green, B. G. (2003). Decline of tactile acuity in aging: A study of body site, blood flow, and lifetime habits of smoking and physical activity. Somatosensory \& Motor Research, 20, 271-279.

Stevens, J. C., \& CHoo, K. K. (1996). Spatial acuity of the body surface over the life span. Somatosensory \& Motor Research, 13, 153-166.

Stevens, J. C., Foulke, E., \& Patterson, M. Q. (1996). Tactile acuity, aging, and Braille reading in long-term blindness. Journal of Experimental Psychology: Applied, 2, 91-106.

Stevens, J. C., \& Patterson, M. Q. (1995). Dimensions of spatial acuity in the touch sense: Changes over the life span. Somatosensory \& Motor Research, 12, 29-47.

Van Boven, R. W., Hamilton, R. H., Kauffman, T., Keenan, J. P., \& 
Pascual-Leone, A. (2000). Tactile spatial resolution in blind Braille readers. Neurology, 54, 2230-2236.

Vega-Bermudez, F., \& Johnson, K. O. (2001). Differences in spatial acuity between digits. Neurology, 56, 1389-1391.

Vega-Bermudez, F., \& Johnson, K. O. (2004). Fingertip skin conformance accounts, in part, for differences in tactile spatial acuity in young subjects, but not for the decline in spatial acuity with aging. Perception \& Psychophysics, 66, 60-67.

Vega-Bermudez, F., Johnson, K. O., \& Hsiao, S. S. (1991). Human tactile pattern recognition: Active versus passive touch, velocity effects, and patterns of confusion. Journal of Neurophysiology, 65, 531-546.

Wallman, J., \& Winawer, J. (2004). Homeostasis of eye growth and the question of myopia. Neuron, 43, 447-468.

Weisser, V., Stilla, R., Peltier, S., Hu, X., \& Sathian, K. (2005). Short-term visual deprivation alters neural processing of tactile form. Experimental Brain Research, 166, 572-582.

\section{NOTES}

1. One of the leading causes of visual impairment is diabetic retinopathy. Diabetes can often be accompanied by peripheral nerve damage (neuropathy), which can afflict the fingers and other extremities. Neuropathy in the fingers reduces spatial tactile acuity. People with diabetic retinopathy who experience this condition may be unable to read braille.

2. Only subjects who had never (1) experienced tingling feelings in their hands and fingers; (2) had calluses due to instrument playing (e.g., guitar, violin); or (3) had diabetes were recruited in this study.

3. For the sake of simplicity, we will sometimes refer to this group of 49 subjects as the "blind subjects."
4. Some of our braille readers were initially confused by the identity of the "jumbo" braille symbols on the upper lines of the dot chart. When first introduced to the chart, a few readers confused the " $\mathrm{f}$ " symbol with "m" and the "h" symbol with "u." The "m" has three dots in the same general configuration as the " $\mathrm{f}$ " except that the lower dot is in the bottom location of the braille cell, rather than in the middle location. The " $\mathrm{u}$ " is similar to the "h," except that the lower two dots are in the bottom two locations of the braille cell.

5 . This level of performance was significantly below the chance level of $25 \%$. Some of the subjects declined to guess the orientation of the Cs on the bottom line of the chart, so these symbols were counted wrong. Therefore, the subjects missed the opportunity to gain correct responses by chance.

6. Scoring reading speed on the visual form of the MNREAD test takes into account that every sentence has exactly 60 characters, corresponding to 10 standard-length words, where one standard-length word is equal to 6 characters. This character-based metric is hard to implement for the braille version of MNREAD sentences, because braille contractions introduce variability in the number of characters per MNREAD sentence. As described in Appendix 2 of Legge, Madison, and Mansfield (1999), we have altered the scoring of the braille version of the test to take into account the number of actual words in the MNREAD sentences. Because the average MNREAD sentence had 11.9 actual words instead of 10 standard-length words, the braille reading speeds were $19 \%$ higher than would have been computed using the standard-length word metric.

(Manuscript received February 3, 2008; revision accepted for publication May 5, 2008.) 